\title{
Influence of Node Number and Orientation of Explants on in Vitro Growth and Development of Potato
}

\author{
Tanuja Buckseth ${ }^{1 *}$, RK Singh ${ }^{1}$, Ashwani K Sharma ${ }^{2}$, Sumita Sharma ${ }^{1}$, \\ Vaishali Moudgil ${ }^{1}$ and Aastha Saraswati ${ }^{1}$ \\ ${ }^{1}$ ICAR-Central Potato Research Institute, Shimla-171001, Himachal Pradesh, India \\ ${ }^{2}$ ICAR-Central Potato Research Station, Kufri-171012, Himachal Pradesh, India
}

Received May 31, 2017; accepted July 5, 2017

\begin{abstract}
Summary Potato (Solanum tuberosum) is one of the most important food crops in the world which can be used in tissue culture techniques, ranging from in vitro propagation via shoot cultures to regeneration of whole plants from protoplasts. The study was undertaken to determine the influence of node number (single or double) and its orientation (horizontal or vertical) on different growth parameters of potato varieties (Kufri Bahar, Kufri Jyoti, Kufri Lauvkar, Kufri Sindhuri and Kufri Chandramukhi). Six to eight cuttings of double node and single node were inserted vertically and horizontally per bottle at an equilateral distance in MS media without any growth regulators. The study revealed that node number, explants orientation, potato varieties, and their interaction had significant effect on different morphological characters viz., microplant height, number of leaves, nodes, roots as well as dry weight.
\end{abstract}

Key words In vitro, Potato, Explants, Orientation, Micropropagation, Solanum.

Potatoes (Solanum tuberosum L.) are one of the essential food crops in the world and are grown in more than 100 countries under temperate, subtropical, and tropical conditions. India has seen a revolution in potato production during recent years (Scott and Suarez 2011). Potatoes are served for either table consumption or as processed products. In addition to being a source of carbohydrates, potatoes also contain high content of protein, vitamin $\mathrm{C}$, fiber, minerals, and have a low fat content (Navarre et al. 2009). The potato is amenable to a number of tissue culture techniques, ranging from in vitro propagation via shoot cultures to regeneration of whole plants from protoplasts. Tissue culture-based hi-tech seed potato production is spreading very fast in the country. Micropropagation at faster rates and free from cultural contamination is an integral component for the success of in vitro mass multiplication of potatoes (Buckseth et al. 2016). In general terms, these all involve the growth of plants, cells, tissues, and organs in sterile conditions, supported by an appropriate culture medium. Media normally contain a mixture of major and minor salts, vitamins, sugar (as a carbon source), and plant growth regulators (Karp et al. 1987). The most widely used formulations are based on that of Murashige and Skoog (1962) which is available commercially. The success of regeneration through plant tissue culture depends upon the explants chosen and the way the explants are placed on the culture medium (Kozak et al. 2013).

*Corresponding author, e-mail: tanujagbpuat@gmail.com DOI: $10.1508 /$ cytologia.83.19
Thus the aim of the present study was to evaluate the influence of node number (single or double) and its orientation (horizontal or vertical) on growth and development of five different potato varieties.

\section{Materials and methods}

The study was carried out at ICAR-Central Potato Research Institute, Shimla. Five different varieties of potato viz. Kufri Bahar, Kufri Jyoti, Kufri Lauvkar, Kufri Sindhuri, and Kufri Chandramukhi (K.C.M) were used. The basic Murashige and Skoog medium without growth regulators was poured in bottles and autoclaved at $121^{\circ} \mathrm{C}$ for $22 \mathrm{~min}$. Six to eight cuttings of double nodes were inserted vertically and horizontally (Fig. 1a, c) per bottle at an equilateral distance. These bottles were marked as double node vertical (DNV) and double node horizontal (DNH). Another six to eight cuttings of a single node were inserted vertically and horizontally (Fig. 1b, d) per bottle at an equilateral distance. These bottles were marked as single node vertical (SNV) and single node horizontal (SNH). The culture tubes were kept for 21 days in a culture room with $16 \mathrm{~h}$ light (irradiance of $60 \mu \mathrm{mol} \mathrm{m}^{-2} \mathrm{~s}^{-1}$ ) and $8 \mathrm{~h}$ dark photoperiodism at $22 \pm 1^{\circ} \mathrm{C}$. Various growth parameters viz. microplant height, root length, number of nodes, leaves and roots, fresh weight as well as dry weight was recorded after 21 days of incubation. In case of roots, as there was secondary branching, only primary roots were counted. Root length was recorded for the longest root in each plant. Fresh and dry weight was taken for all three plantlets along with the 
root. Microplants from each test tube were dried at $80^{\circ} \mathrm{C}$ for $48 \mathrm{~h}$ in the hot air oven and dry weight was recorded after bringing it to room temperature. The experiment was conducted in a completely randomized design. Each treatment comprised four replicates, each replicate consists of four bottles having six to eight plantlets. The analysis of variance was done using the software AGRES and means were separated according to the least significant differences at 0.05 level of probability.

\section{Results and discussion}

The number of nodes (single or double) and its orientation (horizontal or vertical) on the culture medium showed a high influence on the growth and development of different potato varieties. The experimental results

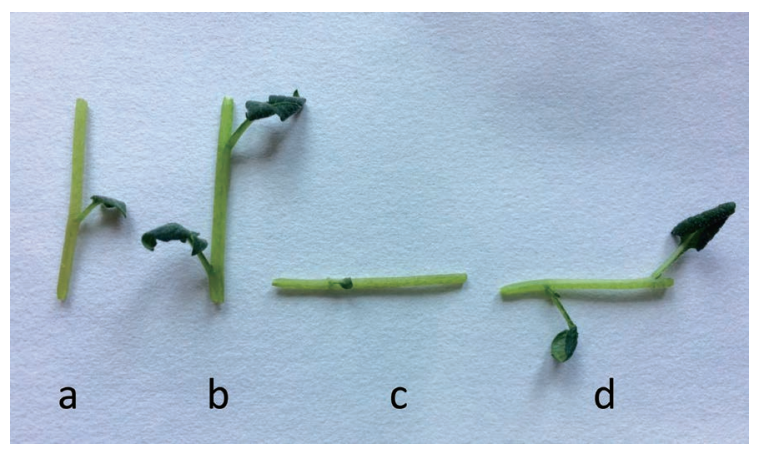

Fig. 1. (a) Single Node Vertical (SNV), (b) Double Node Vertical (DNV), (c) Single Node Horizontal (SNH) and (d) Double Node Horizontal (DNH).
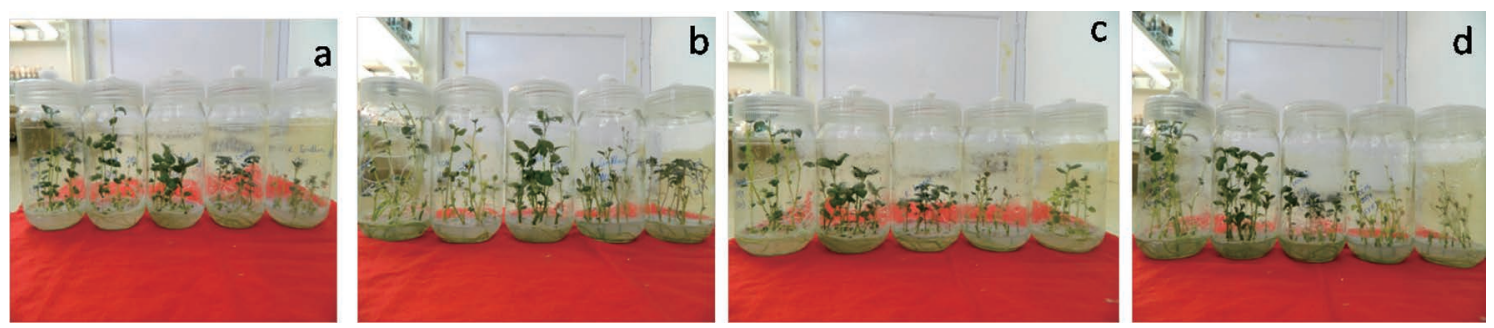

Fig. 2. (a) Double Node Horizontal, (b) Double Node Vertical, (c) Single Node Horizontal, (d) Single Node Vertical of five varieties i.e., Kufri Bahar, Kufri Lauvkar, Kufri Jyoti, Kufri Sindhuri.

Table 1. Effect of number of nodes and its orientation on Microplant Height and No. of Leaves of different potato.

\begin{tabular}{|c|c|c|c|c|c|c|c|c|c|c|}
\hline \multirow{2}{*}{ Variety } & \multicolumn{5}{|c|}{ Microplant height $(\mathrm{cm})$} & \multicolumn{5}{|c|}{ No. of leaves } \\
\hline & DNV & $\mathrm{DNH}$ & SNV & $\mathrm{SNH}$ & Mean & DNV & DNH & SNV & $\mathrm{SNH}$ & Mean \\
\hline K. Bahar & 12.700 & 8.767 & 13.233 & 10.733 & 11.358 & 6.100 & 5.533 & 5.900 & 5.900 & 5.858 \\
\hline K. Jyoti & 5.867 & 3.867 & 9.133 & 6.667 & 6.383 & 4.433 & 4.000 & 4.367 & 3.433 & 4.058 \\
\hline K. Lauvkar & 4.100 & 4.333 & 5.367 & 4.000 & 4.450 & 3.667 & 5.100 & 3.667 & 3.100 & 3.883 \\
\hline K. Sindhuri & 6.200 & 3.633 & 5.900 & 4.900 & 5.158 & 4.433 & 3.100 & 4.767 & 4.000 & 4.075 \\
\hline K.C.M & 8.633 & 7.400 & 7.133 & 7.400 & 7.642 & 6.133 & 4.333 & 4.000 & 4.567 & 4.758 \\
\hline \multirow[t]{2}{*}{ Mean } & 7.500 & 5.600 & 8.153 & 6.740 & & 4.953 & 4.413 & 4.540 & 4.200 & \\
\hline & Variety & MH & $\mathrm{V} \times \mathrm{MH}$ & & & Variety & No. of L & $\mathrm{V} \times \mathrm{L}$ & & \\
\hline $\mathrm{CD}(\mathrm{P}-0.5 \%)$ & 0.956 & 0.855 & 1.912 & & & 0.631 & NS & 1.263 & & \\
\hline $\mathrm{SE}(\mathrm{d})$ & 0.471 & 0.421 & 0.942 & & & 0.311 & 0.278 & 0.623 & & \\
\hline
\end{tabular}


slightly increased the number of regenerated shoots. An increase in shoot numbers was observed when shoots were placed on the medium horizontally (Orlikowska et al. 2000, Debnath 2005, Rajeswari and Palival 2008) or vertically in an inverted position with the shoot tip down (Ziv et al. 1970, Seabrook et al. 1976, Kozak 1991, Orlikowska et al. 2000). There was an increase in the number of roots in Kufri Jyoti (10.8) in comparison to the other four varieties. SNV enhanced the number of roots in Kufri Bahar (7.2), Kufri Jyoti (14.8), and Kufri Lauvkar (7.9). However, in Kufri Sindhuri and K.C.M, DNV increased the number of roots (10.5 and 5.2). The overall results for the number of roots showed that the performance of DNH and $\mathrm{SNH}$ were not satisfactory than that of DNV and SNV. The frequency of root regeneration was highest in case of node explants, either placed vertically or horizontally followed by leaves and internode explants (Tiwari et al. 2016). The present study attributed significant differences in case of number of roots and the orientation of nodal cuttings among all the varieties (Table 2).

In three varieties of potato viz., Kufri Lauvkar, Kufri Jyoti and Kufri Sindhuri, SNH showed enhanced root growth (8.6, 9.3, and $11.3 \mathrm{~cm}$, respectively). However, in Kufri Bahar and K.C.M., root length was increased with
DNV (9.7 and $10.6 \mathrm{~cm}$ ). Sharma et al. reported that root length was significantly enhanced by a single node in Kufri Bahar and double nodes in Kufri Chandramukhi. The present study explains that the genotype is sole responsible to confer the microplants behavior to the kind and position of explants but most of the genotypes respond very well to the vertical orientation. Fresh and dry weight of Kufri Jyoti (352 and $35 \mathrm{mg}$ ) was the highest followed by Kufri Bahar (301 and $24 \mathrm{mg}$ ) and Kufri Lauvkar (194 and 18mg). All the tested varieties did not vary significantly for root length and fresh weight respectively (Table 3 ). Kozak et al. reported that in Cosmos atrosanguineus, the shoots regenerated from defoliated shoot tips placed in an inverted position in relation to the natural orientation were characterized by the highest fresh weight. The performance of DNV and SNV in all the varieties was on the higher side in comparison to $\mathrm{SNH}$ and $\mathrm{DNH}$.

There are many reports about the beneficial effect of the horizontal orientation of explants on the regeneration ability of explants: Myrtus communis (Nobre 1994), Codiaeum variegatum (Orlikowska et al. 2000) Vaccinium vitis-idaea (Debnath 2005), and Albizia odoratissima (Rajeswari and Paliwal 2008). But, in case of the potato this is the first report on the influence of node number

Table 2. Effect of number of nodes and its orientation on No. of nodes and No. of roots of varieties.

\begin{tabular}{|c|c|c|c|c|c|c|c|c|c|c|}
\hline \multirow{2}{*}{ Variety } & \multicolumn{5}{|c|}{ No. of nodes } & \multicolumn{5}{|c|}{ No. of roots } \\
\hline & DNV & $\mathrm{DNH}$ & SNV & $\mathrm{SNH}$ & Mean & DNV & $\mathrm{DNH}$ & SNV & $\mathrm{SNH}$ & Mean \\
\hline K. Bahar & 6.233 & 5.533 & 5.900 & 5.900 & 5.892 & 6.433 & 6.333 & 7.233 & 5.233 & 6.308 \\
\hline K. Jyoti & 4.233 & 4.000 & 3.900 & 2.900 & 3.758 & 12.233 & 6.433 & 14.800 & 10.000 & 10.867 \\
\hline K. Lauvkar & 3.800 & 5.100 & 3.333 & 2.900 & 3.783 & 5.767 & 4.133 & 7.900 & 6.433 & 6.058 \\
\hline K. Sindhuri & 4.533 & 3.100 & 4.767 & 4.000 & 4.100 & 10.533 & 4.667 & 6.800 & 4.567 & 6.642 \\
\hline K.C.M & 5.767 & 4.533 & 3.967 & 4.900 & 4.792 & 5.200 & 4.533 & 4.667 & 4.000 & 4.600 \\
\hline \multirow[t]{2}{*}{ Mean } & 4.913 & 4.453 & 4.373 & 4.120 & & 8.033 & 5.220 & 8.280 & 6.047 & \\
\hline & Variety & Nodes & $\mathrm{V} \times \mathrm{N}$ & & & Variety & Roots & $\mathrm{V} \times \mathrm{R}$ & & \\
\hline $\mathrm{CD}(p-0.5 \%)$ & 0.573 & 0.512 & 1.146 & & & 1.553 & 1.389 & 3.107 & & \\
\hline $\mathrm{SE}(\mathrm{d})$ & 0.282 & 0.253 & 0.565 & & & 0.766 & 0.685 & 1.531 & & \\
\hline
\end{tabular}

Table 3. Effect of number of nodes and its orientation on root length, fresh weight and dry weight of varieties.

\begin{tabular}{|c|c|c|c|c|c|c|c|c|c|c|}
\hline Variety & Orientation & K. Bahar & K. Jyoti & K. Lauvkar & K. Sindhuri & K.C.M & Mean & & $\mathrm{CD}(p-0.5 \%)$ & $\mathrm{SE}(\mathrm{d})$ \\
\hline \multirow[t]{5}{*}{ Root length $(\mathrm{cm})$} & DNV & 9.733 & 6.633 & 8.267 & 8.933 & 10.633 & 8.840 & Variety & NS & 0.966 \\
\hline & DNH & 9.067 & 5.633 & 6.833 & 7.067 & 8.633 & 7.447 & RL & NS & 0.864 \\
\hline & SNV & 9.333 & 7.200 & 8.167 & 10.333 & 7.667 & 8.540 & $\mathrm{~V} \times \mathrm{RL}$ & NS & 1.933 \\
\hline & SNH & 8.333 & 9.367 & 8.667 & 11.333 & 8.433 & 9.227 & & & \\
\hline & Mean & 9.117 & 7.208 & 7.983 & 9.417 & 8.842 & & & & \\
\hline \multirow[t]{5}{*}{ Fresh weight (mg) } & DNV & 395.600 & 402.800 & 213.533 & 195.933 & 124.933 & 266.560 & Variety & 46.756 & 23.049 \\
\hline & DNH & 236.267 & 285.933 & 136.100 & 111.967 & 195.533 & 198.560 & FW & 41.820 & 20.616 \\
\hline & SNV & 317.033 & 370.867 & 214.700 & 134.767 & 217.933 & 251.060 & $\mathrm{~V} \times \mathrm{FW}$ & NS & 46.099 \\
\hline & $\mathrm{SNH}$ & 255.867 & 351.133 & 194.500 & 122.000 & 132.733 & 211.247 & & & \\
\hline & Mean & 301.192 & 352.683 & 196.458 & 141.167 & 167.783 & & & & \\
\hline \multirow[t]{5}{*}{ Dry weight (mg) } & DNV & 29.633 & 45.267 & 20.567 & 16.400 & 10.100 & 24.393 & Variety & 4.595 & 2.265 \\
\hline & DNH & 26.133 & 33.600 & 17.500 & 17.467 & 21.933 & 23.327 & DW & 4.110 & 2.026 \\
\hline & SNV & 19.867 & 31.200 & 18.867 & 13.000 & 12.700 & 19.127 & $\mathrm{~V} \times \mathrm{DW}$ & NS & 4.530 \\
\hline & $\mathrm{SNH}$ & 22.333 & 33.900 & 17.367 & 11.000 & 10.633 & 19.047 & & & \\
\hline & Mean & 24.492 & 35.992 & 18.575 & 14.467 & 13.842 & & & & \\
\hline
\end{tabular}


and orientation of explants on in vitro growth and development suggesting that the vertical orientation with single or double nodes are successful for rapid multiplication of healthy potato microplants.

\section{Acknowledgements}

The authors are grateful to the Indian Council of Agricultural Research, New Delhi, India for providing financial supports and necessary facilities to carry out research work and Dr EP Venkataslam, Sr. Scientist \& Incharge, ICAR-CPRS, Ooty for providing the baseline data to conduct the research.

\section{References}

Buckseth, T., Sharma, A. K., Pandey, K. K., Singh, B. P. and Muthuraj, R. 2016. Methods of pre-basic seed potato production with special reference to aeroponics-A review. Sci. Hortic. 204: $79-87$.

Debnath, S. C. 2005. Micropropagation of lingonberry: influence of genotype, explant orientation, and overcoming TDZ-induced inhibition of shoot elongation using zeatin. HortScience 40: $185-188$.

Karp, A., Jones, M. G. K., Ooms, G. and Bright, S. W. J. 1987. Potato protoplasts and tissue culture in crop improvement. Biotechnol. Genet. Eng. Rev. 5: 1-32.

Kozak, D. 1991. Shoot regeneration from various parts of Narcissus cv. Carlton through tissue culture. Prace Inst. Sad. Kwiac. Rośliny Ozdobne. Ser. B 16: 41-48.

Kozak, D., Pogroszewska, E. and Szmagara, M. 2013. The influence of type and orientation of explants on in vitro growth and development of Cosmos atrosanguineus (Hook.) Voss. Acta Sci. Pol.
Hort. Cult. 12: 41-53.

Murashige, T. and Skoog, F. 1962. A revised medium for rapid growth and bio assays with tobacco tissue cultures. Physiol. Plant. 15: 473-497.

Navarre, D. A., Goyer, A. and Shakya, R. 2009. Nutritional Value of Potatoes: Vitamin, Phytonutrient, and Minerals Content. In: Singh, J. and Kaur, L. (eds.). Advances in Potato Chemistry and Technology. Elsevier, Amsterdam. pp. 395-424.

Nobre, J. 1994. In vitro shoot proliferation of Myrtus communis L. from field-grown plants. Sci. Hortic. 58: 253-258.

Orlikowska, T., Sabała, I. and Kucharska, D. 2000. The effect of leaf and shoot tip removal and explant orientation on axillary shoot proliferation of Codiaeum variegatum Blume var. pictum Muell. Arg. cv. Excellent. Sci. Hort. 85: 103-111.

Rajeswari, V. and Paliwal, K. 2008. In vitro adventitious shoot organogenesis and plant regeneration from seedling explants of Albizia odoratissima L.f. (Benth.). In Vitro Cell. Dev. Biol. Plant 44: 78-83.

Scott, G. and Suarez, V. 2011. Growth rates for potato in India and their implications for industry. Potato J. 38: 100-112.

Seabrook, J. E. A., Cumming, B. G. and Dionne, L. A. 1976. The in vitro induction of adventitious shoot and root apices on Narcissus (daffodil and narcissus) cultivar tissue. Can. J. Bot. 54: 814-819.

Sharma, S., Venkatasalam, E. P., Patial, R., Latawa, J. and Singh, S. 2011. Influence of gelling agents and nodes on the growth of potato microplant. Potato J. 38: 41-46.

Tiwari, V., Singh, R. P., Singh, B. D., Singh, P., Singh, M. K. and Singh, R. K. 2016. Comparative analysis on the effect of trimethoprim and bavistin on direct shoot regeneration in Brahmi (Bacopa monniera) in growth regulator free MS medium. J. Environ. Biol. 37: 383-390.

Ziv, M., Halevy, A. H. and Shilo, R. 1970. Organ and plantlets regeneration of Gladiolus through tissue culture. Ann. Bot. 34: 671-676. 